Tropical Journal of Pharmaceutical Research November 2018; 17 (11): 2169-2176

ISSN: 1596-5996 (print); 1596-9827 (electronic)

(1) Pharmacotherapy Group, Faculty of Pharmacy, University of Benin, Benin City, 300001 Nigeria.

\title{
Curcumin protects trabecular meshwork cells against hydrogen peroxide-induced oxidative stress and apoptosis via Nrf2-keap1 pathway
}

\author{
Yi Luo ${ }^{1,2}$, Hongtao Ding ${ }^{3 *}$, Dujun $\mathrm{Li}^{4}$, Jihong Luo ${ }^{4}$ \\ ${ }^{1}$ Department of Ophthalmology, Wuhan Forth Hospital, ${ }^{2}$ Department of Ophthalmology, Wuhan Puai Hospital, Tongji Medical \\ College, Huazhong University of Science and Technology, ${ }^{3}$ Department of Internal Medicine, Wuhan No. 1 Hospital, Wuhan \\ 430022, ${ }^{4}$ Department of Ophthalmology, Hubei Provincial Hospital of Traditional Chinese Medicine, Hubei Provincial Academy \\ of Traditional Chinese Medicine, Hubei Provincial University of Traditional Chinese Medicine, Hubei 430065, China
}

*For correspondence: Email: Dinghttchb13@163.com

\begin{abstract}
Purpose: To explore the effects and molecular mechanism of action of curcumin on trabecular meshwork cells (TMCs).

Methods: TMCs were isolated from pig eyes and NF-E2-related factor 2 (Nrf2) was knocked down by siRNA transfection. The effect of curcumin on intracellular reactive oxygen species (ROS) was measured by a ROS-specific dye. Annexin V-FITC/propidium iodide (PI) double labeling was applied to determine apoptosis. The expressions of apoptosis-associated proteins and Nrf2-Kelch-like ECHassociated protein 1 (Keap 1) pathway activation were assessed by western blotting, while target gene transcription was analyzed by quantitative real-time polymerase chain reaction (qRT-PCR).

Results: Curcumin reduced the levels of intracellular ROS and apoptosis induced by $\mathrm{H}_{2} \mathrm{O}_{2}$, upregulated B-cell lymphoma-2 (Bcl-2), downregulated Bcl2-associated X (Bax), and activated caspase-3 and nine other proteins $(p<0.05)$. Curcumin reduced the expressions of Nrf2, HO-1, and NQO1, and increased Keap1 in $\mathrm{H}_{2} \mathrm{O}_{2}$-induced TMCs $(p<0.05)$. Moreover, Nrf2 knockdown partly reversed the effect of curcumin on ROS and apoptosis in TMCs induced by $\mathrm{H}_{2} \mathrm{O}_{2}(p<0.05)$.

Conclusion: Curcumin inhibited oxidative stress and apoptosis by Nrf2-Keap1 activation in TMCs. Curcumin is therefore a potential therapeutic agent for the management of glaucoma.
\end{abstract}

Keywords: Curcumin, Oxidative stress, Apoptosis, Glaucoma, Nrf2-Keap1

\begin{abstract}
This is an Open Access article that uses a funding model which does not charge readers or their institutions for access and distributed under the terms of the Creative Commons Attribution License (http://creativecommons.org/licenses/by/4.0) and the Budapest Open Access Initiative (http://www.budapestopenaccessinitiative.org/read), which permit unrestricted use, distribution, and reproduction in any medium, provided the original work is properly credited.
\end{abstract}

Tropical Journal of Pharmaceutical Research is indexed by Science Citation Index (SciSearch), Scopus, International Pharmaceutical Abstract, Chemical Abstracts, Embase, Index Copernicus, EBSCO, African Index Medicus, JournalSeek, Journal Citation Reports/Science Edition, Directory of Open Access Journals (DOAJ), African Journal Online, Bioline International, Open-J-Gate and Pharmacy Abstracts

\section{INTRODUCTION}

Glaucoma, the second leading cause of blindness, affects more than 70 million people and is characterized by progressive degeneration of retinal ganglion cells (RGCs) [1]. Many risk factors for this disorder have been identified, including elevated intraocular pressure (IOP), oxidative stress, apoptosis, alterations of cytokines, and autophagy [2-4]. Elevated IOP, a crucial factor related to RGC death which results from oxidative stress or apoptosis, is associated with biochemical changes in the trabecular meshwork (TM) [5]. The clinical application of 
traditional Chinese medicines have resulted in improvements in treating glaucoma because it reduces IOP and modulates optic nerve nutrition and systemic conditions [6].

NF-E2-related factor 2 (Nrf2), a major protein of oxidative stress regulating, is sequestered by cytoplasmic Keap1 [7]. Numerous studies demonstrated that the Nrf2-Keap pathway attenuates oxidative and apoptotic responses in vivo and in vitro [8]. However, the specific effects of Nrf2 and its regulating manner in the treatment of glaucoma remain unclear. Curcumin, the major extract of turmeric, is derived from Curcuma longa and has been widely used in many countries for centuries [9]. Many studies have suggested that curcumin could be a therapeutic agent for ocular diseases [10].

However, the molecular mechanism of curcumin in treating glaucoma is unclear. In this study, we characterized the protective roles of curcumin on trabecular meshwork cells (TMCs) exposed to $\mathrm{H}_{2} \mathrm{O}_{2}$, and investigated the role of Nrf2-Keap1 in $\mathrm{H}_{2} \mathrm{O}_{2}$-induced oxidative stress and apoptosis.

\section{EXPERIMENTAL}

\section{Chemical and reagents}

Primary antibodies were purchased from Cell Signaling Technology (Beverly, MA, USA). $\mathrm{H}_{2} \mathrm{O}_{2}$ was purchased from the Beyotime Institute of Biotechnology (Shanghai, China). Lipopolysaccharide was purchased from SigmaAldrich (St. Louis, MO, USA). Curcumin (> $98 \%$ pure) was purchased from the National Institutes for Food and Drug Control (Beijing, China).

\section{Isolation and culture of TMCs}

Primary porcine TMCs were obtained from fresh pig eyes, and cultured as previously described [11]. Briefly, the eyes were bisected along the equator. After lens, iris, vitreous, and ciliary body were removed from the anterior part, the trabecular tissue was scraped from the sclera. After digested by collagenase type IV and centrifuged, TMCs were cultured in low glucose Dulbecco's Modified Eagle's Medium (Gibco, Gathersburg, MD, USA) with $10 \%$ fetal bovine serum, penicillin/streptomycin, sodium pyruvate, nonessential amino acids, L-glutamine, and amphotericin B. All reagents were purchased from Invitrogen (Carlsbad, CA, USA).

\section{Intracellular ROS determination}

The intracellular ROS of TMCs were measured by 2,7-dichlorofluorescein diacetate (DCF-DA).
TMCs or si-Nfr2 TMCs were placed into a dark 96-well plate and treated with different concentrations of curcumin at 20,50 and $100 \mu \mathrm{M}$ at $37^{\circ} \mathrm{C}$ for $1 \mathrm{~h}$, and exposed to $\mathrm{H}_{2} \mathrm{O}_{2}$ for another $24 \mathrm{~h}$ and stained by DCF-DA about $30 \mathrm{~min}$ in dark place. The DCF-DA fluorescence was measured with a flow cytometer (FACS Calibur) and the fluorescence was measured with a microplate reader (Thermo Fisher Scientific) with wavelength $488 \mathrm{~nm}$ (excitation) and $520 \mathrm{~nm}$ (emission).

\section{Apoptosis assay}

Quantitative assay of the apoptosis was evaluated by annexin V/FITC detection kit (BD Biosciences). TMCs or si-Nfr2 TMCs were seeded onto a black 96-well plate and treated with curcumin at 20,50 , and $100 \mu \mathrm{M}$ at $37^{\circ} \mathrm{C}$ for $1 \mathrm{~h}$, and exposed to $\mathrm{H}_{2} \mathrm{O}_{2}$ for another $24 \mathrm{~h}$ and harvested for quantitation of apoptosis. The cells were blocked in binding buffer, stained with annexin V/PI for $15 \mathrm{~min}$. The cells were then immediately analysed by fluorescence-activated cell sorting.

\section{Protein extraction and western blotting}

The treated cells were lysed in cold RIPA buffer with a protease and phosphatase inhibitor (Sigma-Aldrich) and centrifuged. Protein concentrations were measured by Pierce BCA Protein Assay Kit (Thermo Scientific) and diluted to equal concentrations with PBS and $5 \times$ SDSPAGE sample loading buffer, then heated to 95 ${ }^{\circ} \mathrm{C}$. Equal amounts of protein were loaded and separated on Invitrogen NuPAGE ${ }^{\mathrm{TM}}$ Bis-Tris gels (10\%), and transferred onto PVDF membranes (Millipore). The membranes were incubated with primary antibodies (1:1,000 dilution) and secondary antibody (1:10,000 dilution). Protein expressions were detected by an ECL system and quantified using Imaging Systems analysis software (VersaDocMp5000).

\section{RNA extraction and RT-PCR}

Total RNA was extracted using TRIzol reagent (Invitrogen Life Technologies,). Equal amounts of RNA were synthesized to cDNA using GoScript ${ }^{\text {TM }}$ (Promega).The target gene expression was detected by a SYBR Green PCR kit (Promega). The primers are shown in Table 1.

Nrf2 knockdown by transfection with smallinterfering RNA (siRNA)

The siRNA against Nrf2 was synthesized by Sangon Biotech Co., Ltd.. Newly isolated TMCs were transfected with Nrf2-specific siRNA 
(si-Nrf, 5'-GCUGAACUCCUUAGACUCATT-3') or negative control by Lipofectamine 2000 (Invitrogen).

Table 1: Primers used for RT-PCR

\begin{tabular}{lll}
\hline Gene & Primer & Sequence \\
\hline Nrf2 & forward & CAGTGACTCGGAAATGGAA \\
& reverse & GAG \\
& AATGGTTGGCTGTGCTTT \\
NQ01 & forward & AGG \\
& AGAGAGCACTGATCGTAC \\
& reverse & CGTAATTGTAAGCAAACTC \\
& TCCTATG \\
HO-1 & forward & GCTCTATCGTGCTCGCATG \\
& reverse & AATTCCCACTGCCACGGTC \\
Keap1 & forward & GTGTGGAGAGGTATGAGC \\
& reverse & CA \\
GADCGTGTCAGCATTGGG \\
H forward & $\begin{array}{l}\text { GTTCCAGTATGATTCCACC } \\
\text { CACGGCAAGTT }\end{array}$ \\
& reverse & $\begin{array}{l}\text { TGCCAGCCCCAGCATCAAA } \\
\text { GGTAGAAGAGT }\end{array}$ \\
\hline
\end{tabular}

\section{Statistical analysis}

Data were analysed using one-way analysis of variance (ANOVA) with Tukey's tests using Prism 6 software. Data are presented as mean \pm standard deviation (SD) and $p<0.05$ was considered statistically significant.

A
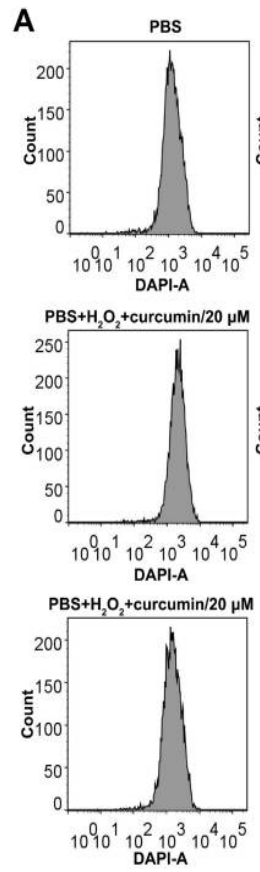
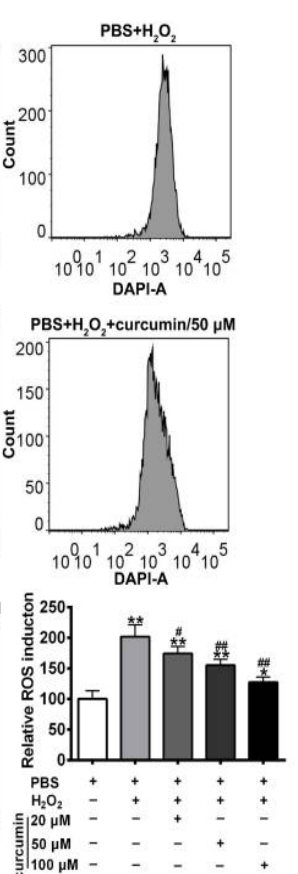

B
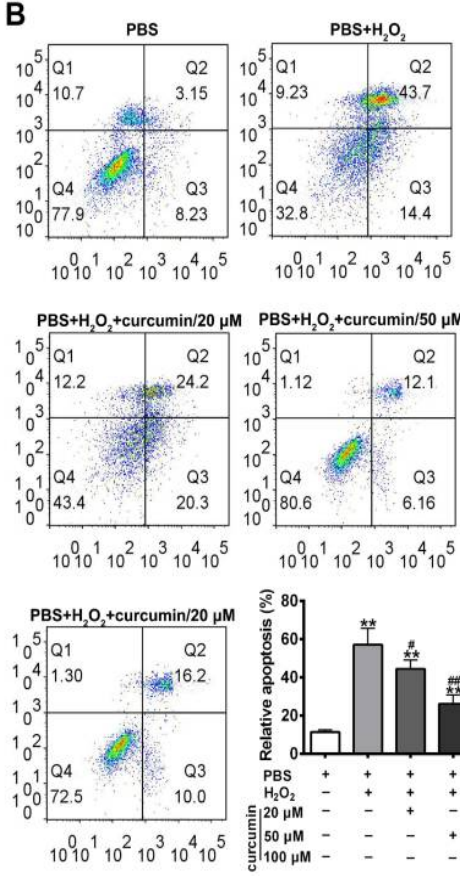

\section{RESULTS}

\section{Curcumin reduced $\mathrm{H}_{2} \mathrm{O}_{2}$-induced oxidative stress in TMCs}

The intracellular ROS were measured by DCFDA. As shown in Figure 1A, the level of intracellular ROS of $\mathrm{H} 2 \mathrm{O} 2$ treated cells was about two times higher than control group $(p<$ 0.01 ), which was inhibited by curcumin in concentration-dependent manner.

\section{Curcumin reduced $\mathrm{H}_{2} \mathrm{O}_{2}$-induced cell apoptosis in TMCs}

Hence, the anti-apoptosis effect of curcumin was confirmed by annexinV/PI staining. As shown in Figure $1 \mathrm{~B}$, the apoptotic cells (Q2 (late apoptosis), $\mathrm{An}^{+} / \mathrm{Pl}^{+}$; $\mathrm{Q} 3$ (early apoptosis), $\mathrm{An}^{+} / \mathrm{PI}^{-}$) were increased in the $\mathrm{H}_{2} \mathrm{O}_{2}$-treated group (from $3.15 \pm 8.23 \%$ in the control to $43.7 \pm 14.4 \%$ in $\mathrm{H}_{2} \mathrm{O}_{2}$ group). When pre-treated with curcumin, apoptotic cells were remarkably decreased $(p<$ 0.01 ) in a concentration-dependent manner. To further explore the mechanism of curcumin on apoptosis, the apoptosis-related proteins were measured by western blotting. As shown in Figure $1 \mathrm{C}$, curcumin increased the expression of $\mathrm{Bcl}-2$ (anti-apoptosis protein), and decreased the

Figure 1: Effect of curcumin on the ROS and apoptosis in $\mathrm{H}_{2} \mathrm{O}_{2}$-treated trabecular meshwork cells (TMCs). (A) Flow cytometry analysis of ROS in TMCs exposed to $1 \mathrm{mM} \mathrm{H}_{2} \mathrm{O}_{2}$. Intracellular ROS were determined by 2,7'dichlorofluorescein diacetate. (B) AnnexinV/PI staining of TMCs. Quadrant Q1 ((An//PI $\left.\left.{ }^{+}\right)\right)$represents necrotic cells, Q2 $\left(\mathrm{An}^{+} / \mathrm{PI}^{+}\right)$represents late apoptotic cells, Q3 $\left(\mathrm{An}^{+} / \mathrm{PI}\right)$ represents early apoptotic cells, and $\mathrm{Q} 4\left(\mathrm{An}^{-} / \mathrm{PI}^{-}\right)$ represents viable cells. The percentage of apoptotic cells was shown in column chart, $(\mathrm{C})_{*}$ Western blotting of apoptosis-related protein expression (Bcl-2, Bax, caspase-3, and caspase-9); $p<0.05$ and ${ }^{\star} p<0.01$ vs. control; ${ }^{\#} p<0.05$ and ${ }^{\# \#} p<0.01$ vs. $\mathrm{H}_{2} \mathrm{O}_{2}$ alone group 
A

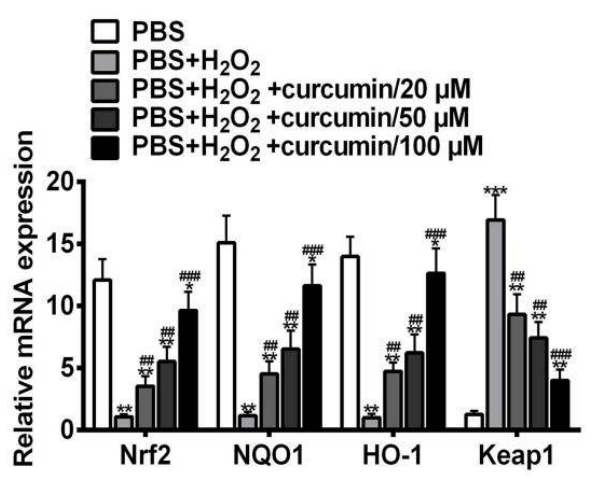

B

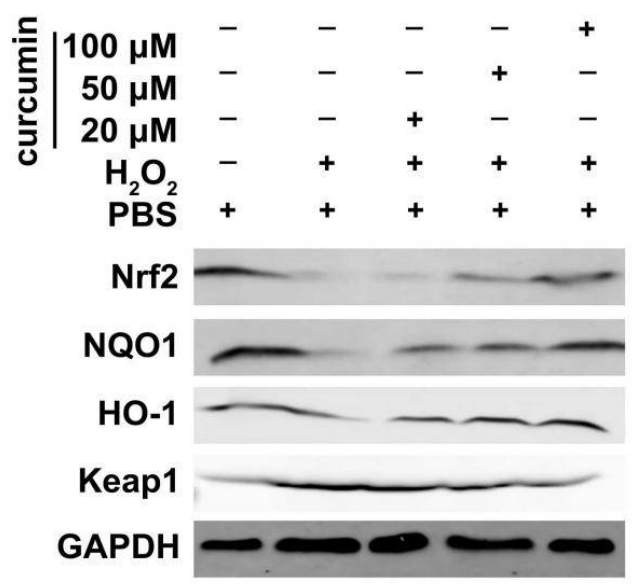

Figure 2: Effect of curcumin on Nrf2-related gene and protein expression in $\mathrm{H}_{2} \mathrm{O}_{2}$-treated TMCs. (A). RT-PCR analysis of Nrf2, NQO1, HO-1, and Keap1 transcription in TMCs. (B) Western blotting of Nrf2-Keap1-related protein expression (Nrf2, NQO1, HO-1, and Keap1); Quadrant Q1 ((An/PI $\left.{ }^{+}\right)$) represents necrotic cells, Q2 $\left(\mathrm{An}^{+} / \mathrm{PI}^{+}\right)$represents late apoptotic cells, $\mathrm{Q} 3\left(\mathrm{An}^{+} / \mathrm{PI}\right)$ represents early apoptotic cells, and $\mathrm{Q} 4\left(\mathrm{An}^{-} / \mathrm{PI}^{-}\right)$represents viable cells. The percentage of apoptotic cells was shown in column chart, $(\mathrm{C})$ Western blotting of apoptosisrelated protein expression (Bcl-2, Bax, caspase-3, and caspase-9); $p<0.05$ and ${ }^{* *} p<0.01$ vs. control; ${ }^{*} p<0.05$ and ${ }^{\# \#} p<0.05$ vs. $\mathrm{H}_{2} \mathrm{O}_{2}$ alone group.

expressions of caspase-3, caspase-9, and Bax (pro-apoptosis protein), in concentrationdependent manner. The results demonstrate that curcumin reduced $\mathrm{H}_{2} \mathrm{O}_{2}$-induced apoptosis in TMCs.

Curcumin reduces Nrf2, NQO1, and HO-1 expression, and increases Keap1 in $\mathrm{H}_{2} \mathrm{O}_{2}$ induced TMCs

The gene and protein expressions of $\mathrm{Nrf2}$, Keap1, NQO1, and $\mathrm{HO}-1$ in $\mathrm{H}_{2} \mathrm{O}_{2}$-induced TMCs were investigated. As shown in Figure $2 \mathrm{~A}$, gene expressions of Nrf2, $\mathrm{HO}-1$, and NQO1 were increased and Keap1 was decreased, indicating activation of the Nrf2-keap pathway. Curcumin significantly inhibited $\mathrm{H}_{2} \mathrm{O}_{2}$-induced genetic transcription dysregulation in a concentrationdependent manner. In parallel, protein expression was consistent with the genetic transcription results (Figure $2 \mathrm{~B}$ ).

\section{Nrf2 knockdown reverses the effect of curcumin on the Nrf2-Keap1 signaling pathway}

To further characterize the role of $\mathrm{Nrf2}$ in the regulation of curcumin on the expression of Nrf2Keap1 pathway target proteins, Nrf2 siRNA was used to to knockdown the expression of Nrf2 in TMCs. The transfection efficiency of the knockdown was confirmed by western blotting and RT-PCR analysis. The Nrf2 mRNA and protein expression in the si-Nrf2 group were decreased when compared with the sc-Nrf2 group (Figure 3), and the expression of target genes and proteins changed accordingly. The expressions of $\mathrm{Nrf} 2, \mathrm{HO}-1$, and $\mathrm{NQO} 1$ were much lower and Keap1 much higher of si-Nrf cells after treated by $\mathrm{H}_{2} \mathrm{O}_{2}$, which were reversed by curcumin in concentration-dependent manner. The protein expressions (Figure 3 B) were consistent with the genetic transcription results (Figure $3 \mathrm{~A}$ ).

\section{Nrf2 knockdown reverses the effect of curcumin on oxidative stress}

The si-Nrf TMCs were also used to determine the effect of $\mathrm{Nrf2}$ on curcumin against $\mathrm{H}_{2} \mathrm{O}_{2}$-induced oxidative stress. The levels of intracellular ROS in the si-Nrf2 group increased when compared with the sc-Nrf2 group (Figure $4 \mathrm{~A}$ ), which was greatly enhanced by $\mathrm{H}_{2} \mathrm{O}_{2}$ in Si-Nrf cells. The intracellular $\mathrm{ROS}$ of $\mathrm{H}_{2} \mathrm{O}_{2}$-treated si-Nrf cells were decreased by curcumin in a concentrationdependent manner.

\section{Nrf2 knockdown reverses the effect of curcumin on apoptosis}

Si-Nrf TMCs were also used to determine the effect of $\mathrm{Nrf} 2$ on curcumin against $\mathrm{H}_{2} \mathrm{O}_{2}$-induced apoptosis. The amount of apoptotic cells of the si-Nrf group was higher than that of the sc-Nrf group, and greatly enhanced by $\mathrm{H}_{2} \mathrm{O}_{2}$ in si-Nrf cells. Curcumin inhibited $\mathrm{H}_{2} \mathrm{O}_{2}$-induced apoptosis of si-Nrf cells in a concentration-dependent manner. To further confirm the results of apoptosis, the apoptosis-related proteins, 
A

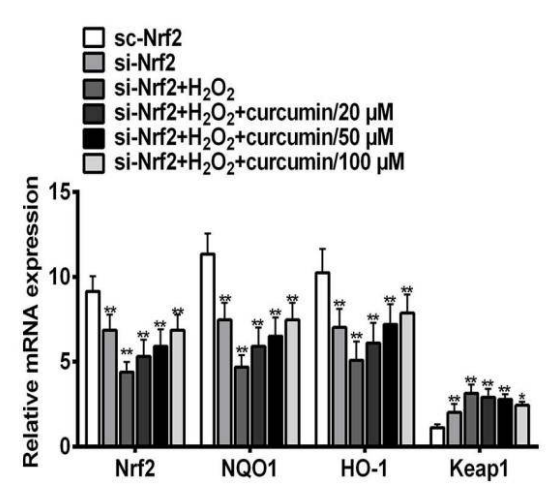

B

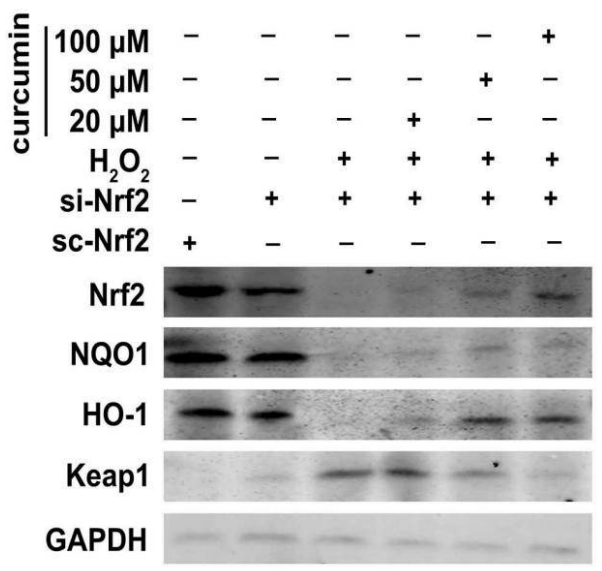

Figure 3: Nrf2 knockdown partly blocked the effects of curcumin on Nrf2 and related protein expression. (A) RTPCR analysis of Nrf2, NQO1, HO-1, and Keap1 transcription in Nrf2 knockdown (si-Nrf) trabecular meshwork cells (TMCs). (B) Western blotting of Nrf2-Keap1-related protein expression (Nrf2, NQO1, HO-1, and Keap1) in si-Nrf TMCs; (Nrf2, NQO1, HO-1, and Keap1); Quadrant Q1 $\left(\left(\mathrm{An}^{-} / \mathrm{PI}^{+}\right)\right)$represents necrotic cells, Q2 $\left(\mathrm{An}^{+} / \mathrm{PI}^{+}\right)$ represents late apoptotic cells, Q3 $\left(\mathrm{An}^{+} / \mathrm{PI}\right)$ represents early apoptotic cells, and $\mathrm{Q} 4\left(\mathrm{An}^{-} / \mathrm{Pl}^{-}\right)$represents viable cells. The percentage of apoptotic cells was shown in column chart, (C) Western blotting of apoptosis-related protein expression (Bcl-2, Bax, caspase-3, and caspase-9); ${ }^{*} p<0.05$ and ${ }^{\star \star} p<0.01$ vs. control; $\#<0.05$ and ${ }^{\# \#} p$ $<0.01$ vs. $\mathrm{H}_{2} \mathrm{O}_{2}$ alone group

A

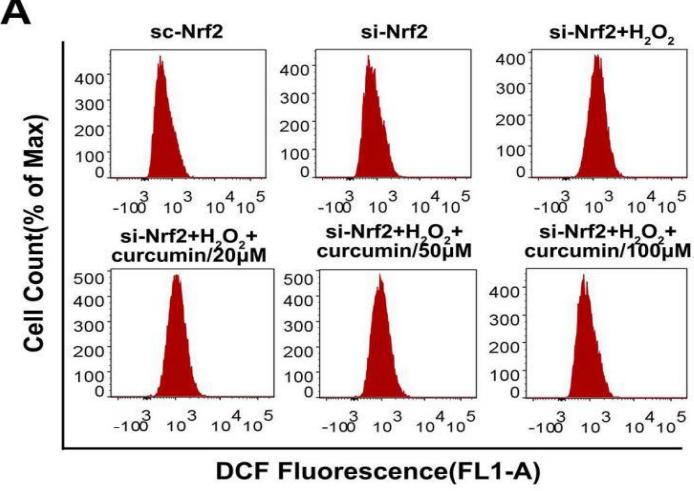

B

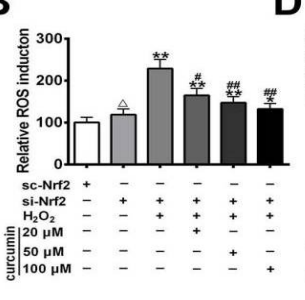

D

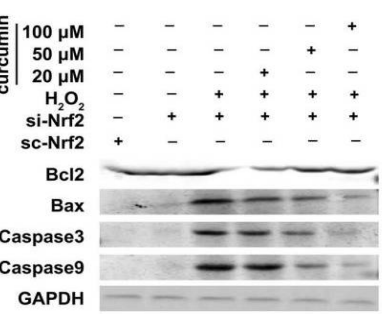

C

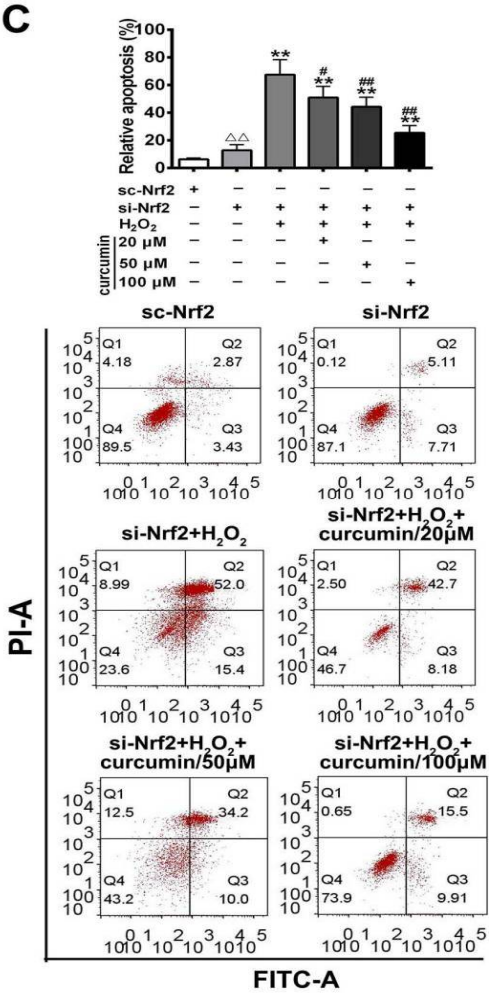

Figure4: Nrf2 knockdown reversed the effects of curcumin against oxidative stress and apoptosis in TMCs. (A) Flow cytometry analysis of reactive oxygen species (ROS)in si-Nrf2 TMCs exposed to $1 \mathrm{mM} \mathrm{H}_{2} \mathrm{O}_{2}$. Intracellular ROS were determined by 2, 7-dichlorofluorescein diacetate. (B) Flow cytometry analysis of si-Nrf2 TMC apoptosis by double staining with annexinV/propidium iodide. (C) Western blotting analysis of Bcl-2, Bax, caspase 3 , and caspase-9; $p<0.05$ and ${ }^{* *} p<0.01$ vs. control; ${ }^{\#} p<0.05$ and ${ }^{\# \#} p<0.05$ vs. $\mathrm{H}_{2} \mathrm{O}_{2}$ alone group.

caspase-3, caspase-9, Bcl-2, and Bax were measured both in sc-Nrf and si-Nrf cells. The expressions of caspase-3, caspase-9, and Bax were increased and $\mathrm{Bcl}-2$ decreased in the si-Nrf group compared with the sc-Nrf group, and the effects were enhanced by $\mathrm{H}_{2} \mathrm{O}_{2}$ in si-Nrf cells. Curcumin decreased the expression of caspase3 , caspase-9, and Bax and increased Bcl-2 in a concentration-dependent manner. 


\section{DISCUSSION}

Oxidative stress is one of the risk factors for glaucoma, and many studies have reported that local oxidative radicals are a determining factor in the pathogenesis of glaucoma [12]. Long-term oxidative damage may lead to the progressive loss of TMCs and glaucoma. Himori et al reported a close relationship between clinical ocular parameters and systemic oxidative stress parameters in 73 patients with normal-tension glaucoma [13]. Their study indicated that skin autofluorescence and 8-hydroxy-2'deoxyguanosine, two markers of oxidative stress, may contribute to the pathogenesis of glaucomatous optic neuropathy.

Curcumin, a natural compound that has many biological properties including anti-inflammation, antiviral, antifungal, and anticancer activities, has been suggested to be an effective treatment for several ocular diseases, such as glaucoma [12]. Some studies have reported that curcumin exhibited antioxidant properties in neurodegenerative diseases, and was associated with activation of the Nrf2 cytoprotective pathway [14]. This study indicate that curcumin decreased the level of ROS in $\mathrm{H}_{2} \mathrm{O}_{2}$-induced TMCs and was associated with the activation of the Nrf2 signaling pathway, which were consistent with the results of previous studies.

Apoptosis is a physiological cell death mechanism that plays a crucial role in glaucoma. It is thought that the ultimate cause of irreversible blindness in this disease is RGC apoptosis [15]. The application of a new imaging technique called "detection of apoptosis retinal cells" (DARC) has shown that the level of RGC apoptosis is predictive of disease severity in patients with glaucomatous neurodegeneration [16]. Moreover, treatment with agents that inhibit RGC apoptosis attenuate glaucoma $[17,18]$. Apoptosis is initially characterized by a series of morphological changes, including cellular shrinkage, membrane blebbing, and nuclear chromatin condensation. Apoptotic programs are related to two pathways and involve the activation of a series of caspases [19]. The upstream caspase for the intrinsic pathway (also known as the membrane receptor-mediated pathway) is caspase-9 and the downstream effector is caspase-3 [20].

The intrinsic pathways are closely-regulated by the Bcl-2 family, which includes anti-apoptotic members (Bcl-2 and $\mathrm{Bcl}-\mathrm{XI}$ ) and pro-apoptotic members (Bax and Bak)[21]. This results indicate that curcumin treatment prevent $\mathrm{H}_{2} \mathrm{O}_{2}$-induced
TMCs apoptosis, with downregulation of cleaved caspase-3, caspase- 9 , and Bax, and upregulation of $\mathrm{Bcl}-2$ protein. More importantly, analyses of apoptosis showed that high concentrations of curcumin ( 50 and $100 \mu \mathrm{M})$ not only decreased the apoptosis of TMCs, but also of necrosis cells, indicating that curcumin did not cause secondary necrosis and immune responses.

Nrf2, which is sequestered by Keap1, is an important transcription factor under oxidative stress. Nrf2-Keap1 has been reported to play an important role in the regulation of oxidative stress and the apoptosis of RGCs[22]. Lycium barbarum polysaccharides protect the retina after ischemia-reperfusion, partially by activation of Nrf2 [23]. Berberine could ameliorate methotrexate-induced oxidative stress and apoptosis by activating the $\mathrm{Nrf} / \mathrm{HO}-1$ pathway and PPARy in vivo [24]. Curcumin has similar effects on oxidative damage. Dai et al reported that curcumin inhibited quinocetone-induced oxidative stress, apoptosis, and inflammation via $\mathrm{Nrf} / \mathrm{HO}-1$ and the NF-kB pathway in human hepatocytes [25]. However, the Nrf2-mediated molecular mechanism of curcumin remains unclear.

In the present study, the results showed that curcumin activated the Nrf2-Keap1 signaling pathway and regulated target gene expression in $\mathrm{H}_{2} \mathrm{O}_{2}$-induced TMCs, resulting in alleviation of both oxidative stress and apoptosis in TMCs. Moreover, Nrf2 knockdown partly reversed the inhibitory effect of curcumin on ROS and apoptosis in $\mathrm{H}_{2} \mathrm{O}_{2}$-induced TMCs. These results strongly suggest that curcumin inhibit oxidative stress and apoptosis by Nrf2-Keap1 signaling pathway. Overall, the results indicate that curcumin has a protective effect against $\mathrm{H}_{2} \mathrm{O}_{2}$ induced oxidative stress and apoptosis of TMCs via the Nrf2-Keap1 signaling pathway.

\section{CONCLUSION}

The results of the present study provide the experimental basis for the possible clinical use of curcumin in the management of certainly inflammatory diseases, as well as the possibility of its development as a therapeutic agent for the treatment of glaucoma.

\section{DECLARATIONS}

\section{Acknowledgement}

This work was supported by funding entitled "Studies on the molecular mechanism of the treatment of San Xiao Nei Zhang Fang for 
diabetic retinopathy" (grant no. JDZX2014Y10), and funding entitled "Studies on the mechanism of prevention and treatment of San Xiao Nei Zhang Fang for the diabetic retinopathy based on the IRE1 pathway" (grant no. JDZX2014Z09).

\section{Conflict of interest}

The authors declare that no conflict of interest is associated with this work.

\section{Contribution of authors}

We declare that this work was done by the researchers listed in this article. All liabilities related with the content of this article will be borne by the authors. Hongtao Ding designed all the experiments and revised the paper. Yi Luo and Dujun Li performed the experiments, Jihong Luo wrote the paper.

\section{REFERENCES}

1. Kaur H, Patro I, Tikoo K, Sandhir R. Curcumin attenuates inflammatory response and cognitive deficits in experimental model of chronic epilepsy. Neurochem Int. 2015; 89(1): 40-50.

2. Aronica $E$, Bauer $S$, Bozzi $Y$, Caleo $M$, Dingledine $R$, Gorter JA, Henshall DC, Kaufer D, Koh S, Löscher W. Neuroinflammatory targets and treatments for epilepsy validated in experimental models. Epilepsia. 2017; 58 (Supp/ 3): 27-38.

3. Abderrazak A, Syrovets $T$, Couchie $D$, El KH, Friguet $B$, Simmet $T$, Rouis M. NLRP3 inflammasome: From a danger signal sensor to a regulatory node of oxidative stress and inflammatory diseases. Redox Biology. 2015; 4(C): 296-307.

4. Kesherwani V, Nandi SS, Sharawat SK, Shahshahan HR, Mishra PK. Hydrogen sulfide mitigates homocysteinemediated pathological remodeling by inducing miR-133a in cardiomyocytes. Molecul Cellul Biochem. 2015; 404(2): 1-10.

5. Weinreb RN, Aung T, Medeiros FA. The pathophysiology and treatment of glaucoma: a review. JAMA. 2014; 311(18): 1901-1911.

6. Mi XS, Zhong JX, Chang RC, So KF. Research advances on the usage of traditional Chinese medicine for neuroprotection in glaucoma. J Integr Med. 2013; 11(4): 233-240.

7. Battino M, Gianpieri F, Pistollato $F$, Sureda A, Oliveira $R$, Pittala V, Fallarino F, Nabavi SF, Atanasov AG, Nabavi $S M$. Nrf2 as regulator of innate immunity: $A$ molecular Swiss army knife! Biotechnol Adv 2018; 36(2): 358-370.

8. Khan NM, Ahmad I, Haqqi TM. Nrf2/ARE pathway attenuates oxidative and apoptotic response in human osteoarthritis chondrocytes by activating ERK1/2/ELK1P70S6K-P90RSK signaling axis. Free Radic Biol Med. 2018; 116: 159-171.
9. Prasad S, Gupta SC, Tyagi AK, Aggarwal BB. Curcumin, a component of golden spice: from bedside to bench and back. Biotechnol Adv. 2014; 32(6): 1053-1064.

10. Wang $L-L$, Sun $Y$, Huang $K$, Zheng $L$. Curcumin, a potential therapeutic candidate for retinal diseases. Molecul Nutrit Food Res 2013; 57(9): 1557-1568.

11. Stamer WD, Seftor RE, Snyder RW, Regan JW. Cultured human trabecular meshwork cells express aquaporin-1 water channels. Curr Eye Res. 1995; 14(12): 10951100.

12. Pescosolido N, Giannotti R, Plateroti AM, Pascarella A, Nebbioso M. Curcumin: therapeutical potential in ophthalmology. Planta Med. 2014; 80(4): 249-254.

13. Himori N, Kunikata H, Shiga Y, Omodaka K, Maruyama $K$, Takahashi H, Nakazawa T. The association between systemic oxidative stress and ocular blood flow in patients with normal-tension glaucoma. Graefe's Archive Clin Exptal Ophthalmol. 2016; 254(2): 333-341.

14. Carmona-Ramirez I, Santamaria A, Tobon-Velasco JC, Orozco-lbarra M, Gonzalez-Herrera IG, PedrazaChaverri J, Maldonado PD. Curcumin restores Nrf2 levels and prevents quinolinic acid-induced neurotoxicity. J Nutrit Biochem 2013; 24(1): 14-24.

15. Yucel YH, Zhang Q, Weinreb RN, Kaufman PL, Gupta N. Effects of retinal ganglion cell loss on magno-, parvo-, koniocellular pathways in the lateral geniculate nucleus and visual cortex in glaucoma. Prog Retin Eye Res. 2003; 22(4): 465-481.

16. Cordeiro MF, Normando EM, Cardoso MJ, Miodragovic $S$, Jeylani S, Davis BM, Guo L, Ourselin S, A'Hern R, Bloom PA. Real-time imaging of single neuronal cell apoptosis in patients with glaucoma. Brain. 2017; 140(6): 1757-1767.

17. Huang $S$, Huang $P$, Lin Z, Liu X, Xu X, Guo L, Shen $X, L i$ $C$, Zhong $Y$. Hydrogen sulfide supplement attenuates the apoptosis of retinal ganglion cells in experimental glaucoma. Exp Eye Res. 2018; 168: 33-48.

18. Zhu K, Zhang ML, Liu ST, Li XY, Zhong SM, Li F, Xu GZ, Wang Z, Miao Y. Ghrelin Attenuates Retinal Neuronal Autophagy and Apoptosis in an Experimental Rat Glaucoma Model. Invest Ophthalmol Vis Sci. 2017; 58(14): 6113-6122.

19. Wong RS. Apoptosis in cancer: from pathogenesis to treatment. J Exp Clin Cancer Res. 2011; 30(1): 87-95.

20. Reed JC. Apoptosis-targeted therapies for cancer. Cancer Cell. 2003; 3(1): 17-22.

21. Reed JC. BCl-2 family proteins: regulators of apoptosis and chemoresistance in hematologic malignancies. Semin Hematol. 1997; 34(4): 9-19.

22. Liu $Y-M$, Chu $X-Y$, Zhang $H-Y$. Activating or Inhibiting Nrf2? Trend Pharmacol Sci. 2017; 38(11): 953-958.

23. He M, Pan H, Chang RC, So KF, Brecha NC, Pu M. Activation of the Nrf2/HO-1 antioxidant pathway contributes to the protective effects of Lycium barbarum polysaccharides in the rodent retina after ischemiareperfusion-induced damage. PLoS One. 2014; 9(1): e84800.

Trop J Pharm Res, November 2018; 17(11): 2175 
24. Mahmoud AM, Hozayen WG, Ramadan SM. Berberine ameliorates methotrexate-induced liver injury by activating Nrf2/HO-1 pathway and PPARY, and suppressing oxidative stress and apoptosis in rats. Biomed Pharmacother. 2017; 94: 280-291.
25. Dai C, Li B, Zhou Y, Li D, Zhang S, Li H, Xiao X, Tang S. Curcumin attenuates quinocetone induced apoptosis and inflammation via the opposite modulation of Nrf2/HO-1 and NF-kB pathway in human hepatocyte L02 cells. Food Chem Toxicol. 2016; 95: 52-63. 